\title{
3 Determinants of Protection systems
}

THE AVAILABILITy OF extraterritorial protection depends on a large number of factors. Do I have enough money to flee? Does my potential host state have the resources to protect me? Is there a flight connection to that host country? Can I get a passport? An entry visa? Is that country obliged to admit me? Will I really be admitted? Or will they send me back? Some of these factors are linked to law; others are not. In the following, we shall attempt to systematize those factors of a legal nature; in so doing, we find that not all of them are catered for in legal norms on extraterritorial protection. Certain questions asked by the protection seeker find their answer in norms relating to migration at large.

To reach safety, a protection seeker simply has to migrate. This she has in common with other categories of persons who cross borders for reasons unrelated to protection in the narrow sense. That commonality is a risky one, and it can be approached in a particularist as well as a universalist fashion. 


\section{CHAPTER 3}

It enables particularist political discourse to relegate protection seekers to the categories of 'migrants' or, indeed, 'illegal migrants'. ${ }^{253}$ This redefinition makes it easier to expose protection seekers to deflection and exclusion. ${ }^{254}$ Certainly, reducing protection seekers to 'illegal migrants', pure and simple, adds insult to the injury of the human rights violations triggering flight. To counter such tendencies, some refugee lawyers and advocacy organisations argue that issues of extraterritorial protection should be strictly severed from the discussion of migration. This is risky too, as access to extraterritorial protection is often contingent on the rules steering migration at large. A deliberate one-eyed approach tends to lose itself in the rights contained in the 1951 Refugee Convention and omits the impact visa requirements have on their enjoyment.

Thus, the discussion of extraterritorial protection and migration seems to be caught between two extremes. The search for extraterritorial protection may neither be reduced to the quest for greener pastures, nor artificially decoupled from its migrational dimensions. After highlighting this double risk, we shall focus on access to extraterritorial protection and control of migration by host countries, proposing an approach that keeps them conceptually apart, without turning a blind eye to their factual interlinkages.

253 An antidote to such confusion is the rigorous separation of means and motivation. Protection seekers may use the same means-i.e. migratory channels-as other categories of migrants, but their motivation is different. See J. Crisp, Policy Challenges of the New Diasporas: Migrant Networks and their Impact on Asylum Flows and Regimes, Report WPTC-99-05 (1999, UNHCR Policy Research Unit, Geneva), p. 9. -For the purpose of this work, we prefer the term 'undocumented migrants'. This term has been defined in the Cairo Conference Programme of Action as comprising 'persons who do not fulfil the requirements established by the country of destination to enter, stay or exercise an economic activity'. Programme of Action, International Conference on Population and Development, Cairo, 5-13 September 1994, para. 10.15, UN Doc. No. A/CONF.171/13.

254 Sometimes, undocumented migration is named-and brandished-in the same vein as trafficking, sexual exploitation in host countries and other forms of modern slave trade, or the smuggling of narcotic substances. By crafting such linkages, protection seekers are made subject to an unwarranted 'guilt by association'. Therefore, it is worth reiterating that protection seekers often have no choice but to use unorthodox methods of flight, including the services rendered by human smugglers. It is important to recall that the illicit market of smuggling is not created by would-be protection seekers attempting to leave their countries of origin, but rather by state-crafted policies. The demand stems from an interplay of the occurence of human rights violations in countries of origin, and the ever more restrictive immigration and admission policies of potential host states. 
To facilitate our understanding, we shall describe migration control and extraterritorial protection as systems. ${ }^{255}$ This implies, among other things, that both aim at serving specific functions. The function of migration control is the production of a population on a given territory through the regulation of transborder movement. More specifically, the system functions by managing the inflow, presence, and outflow of non-citizens on state territory. The code used for running this system is whether a person is allowed access to state territory, or not (access/deflection).

It is important to recall that extraterritorial protection is qualitatively different from migration control. The former is not a sub-system of the latter, as both pursue different functions. The function of extraterritorial protection is to produce a subsidiary form of human rights protection. Or, more pointedly, and at the risk of being misunderstood, one could claim that extraterritorial protection aims at producing refugees. ${ }^{256}$ Be that as it may, the system of extraterritorial protection attempts to realize its function by determining aliens that are defined to be in need of its benefits, and by according these benefits to them. The code underlying extraterritorial protection is whether a person is entitled to extraterritorial protection, or not (protection/rejection).

${ }^{255}$ Luhmann has described systems as 'Identitäten [...], die sich in einer komplexen und veränderlichen Umwelt durch Stabilisierung einer Innen/Außen-Differenz erhalten'. ['Identities [...], which sustain themselves in a complex and changing environment by stabilising an interior/exterior-difference'. Translation by this author]. N. Luhmann, Zweckbegriff und Systemrationalität (1991, Suhrkamp, Frankfurt/Main), p. 175. By borrowing parts of its terminology, we do not purport to do justice to the discipline of systems theory, whose explicatory interests are much more far-reaching than the more modest ones pursued in this work.

${ }^{256}$ This claim does not distribute guilt onto a certain actor. To be sure, it does not say that host states are creating refugees by virtue of an ominous pull effect. To illustrate this claim further, we may revert to Soguk, who has depicted the refugee as a product of statecraft and territoriality. To him, 'the figure of the refugee is functionally central to statecraft even in his socially produced, discourse-bound marginality, a marginality that is vitally productive of the normative centrality of the citizen/nation/state hierarchy in life'. N. Soguk, States and Strangers. Refugees and Displacements of Statecraft (1999, University of Minnesota Press, Minneapolis/London), p. 244. Put in somewhat simpler terms, the protection seeker represents the 'other' which enables the citizen to perceive her identity. It makes sense that states 'fight' this form of otherness, be it in the form of refugee-producing 'root causes' or by repeatedly alluding to the need of avoiding a 'mass influx' of protection seekers. Countering this 'other' means adding value to the 'id', that is, the identity produced by citizenship. 


\section{CHAPTER 3}

There should be little doubt that these differences are rather fundamental. ${ }^{257}$ The concept of two dedicated systems suggests that it is not functional if one system performs tasks that should properly be performed within the other system. This would be the case if the protection system allowed persons not in need of protection to bypass migration control, or if the control system denied refuge on behalf of the system of extraterritorial protection. Let us illustrate this by giving two examples-one related to the return of rejected protection seekers, and the other to the deflection of would-be beneficiaries of extraterritorial protection. First, it has been claimed that failure to return rejected asylum seekers endangers the credibility of the protection system. ${ }^{258}$ As protection is a scarce commodity, it is of interest that only those with a valid claim enter the system of extraterritorial protection, thereby evading the risk of removal under the system of migration control. As both systems draw on the same financial base, a free rider in the protection system would take resources from individuals who are in real need of protection. The nonreturn of rejected cases runs counter to the repartition of tasks between both systems, as the protection system never 'hands over' the rejected person to the control system, thus colonising its functions.

To be sure, this constellation can also be turned around. It is undesirable that potential beneficiaries of the protection system are denied access to its benefits by the control system. This is what happens when the fear of unauthorized immigration incites states to block access for bona fide protection seekers as well. In this example, the state would take a free ride by saving protection expenses. This free ride is to the detriment of the would-be protection seeker. If the credibility of protection systems is endangered by the non-return of rejected cases, it is equally endangered by indiscriminate deflection policies.

These examples may suffice to illustrate that both systems possess the capacity to interfere with each other, or, indeed, to colonize each other.

${ }^{257}$ However, there is also a fundamental commonality between migration control and refugee protection. Both systems operate in the same medium, namely law. Therefore, one could describe both migration control and extraterritorial protection as sub-systems of the legal system. To be sure, the legal system operates with the code legal/illegal, which is an abstraction of the codes access/deflection and protection/rejection. If one chooses to conceive both migration control and extraterritorial protection as sub-systems of law, it is important to realize that they are not hierarchically related to each other.

258 IGCARMP, Report on Asylum Procedures. Overview of Policies and Practices in IGC Participating States (1997, IGCARMP, Geneva), Introduction, p. VII. 
This is so because their fields of operation overlap. The overlapping area is of utmost importance for our further work. In the present chapter, we shall attempt to sketch a rough design of how extraterritorial protection and migration control interact, from the perspective of both host states and the protection seeker.

\subsection{The State Perspective}

The availability of protection hinges to a large extent on the way its costs are distributed..$^{259}$ This is clear not only from domestic social policies, but from international refugee law as well. One of the prime interests of states is to manage the costs of protection systems-be they fiscal, social or political. In this context, 'to manage' implies to keep costs within certain limits. Such limits can be informed by a wide range of factors, ranging from fiscal calculations to strong ethical convictions to a feeling for the politically feasible and opportune. Needless to say, these limits are beyond objective assessment. Setting them means to mould the conflict between universalism and particularism into the form of a specific political decision. ${ }^{260}$

From the outset, we should recall the deficiencies of a cost-focused perspective. One is the tacit assumption that protection systems generate net costs rather than net benefits for a host state. As history has shown, this assumption need not be a correct one. ${ }^{261}$ Another deficiency is the fuzziness of cost calculation. The sum of fiscal costs generated by protection systems will vary, depending on which costs we decide to regard as protection-related and the time frame we choose to look at. A time frame spanning a short period will catch most of the integration

259 Generally on the relationship between rights and costs: S. Holmes and C. Sunstein, The Cost of Rights: Why Liberty Depends on Taxes (1999, W.W. Norton, New York).

${ }^{260}$ Determining the limits for 'acceptable' costs is challenging not only on the domestic level, but in a supranational setting as well. In a later chapter, we shall track the immense difficulties states have when deciding on common limits for the purpose of burdensharing. See chapter 8.3 .2 below.

261 The large-scale success of resettlement policies by Western countries in the aftermath of World War II shows quite graphically that protection seekers are readily received where they fill the needs of the labour market. See, e.g. K. Salomon, Refugees in the Cold War (1991, Lund University Press, Lund), pp. 197-217. However, in his analysis, Salomon is careful not to reduce resettlement only to be a mere labour-market transaction. 


\section{CHAPTER 3}

costs, while neglecting the integration benefits. A time frame covering a longer period will probably turn costs into benefits, provided that integration is successful. The quantification of social and political costs is probably even more dubious: we may all know such costs when we see them, but we are at pains to measure them. Therefore, in the following, we shall limit ourselves to fiscal costs. Finally, a perspective focusing on costs runs the risk of depicting host states as cynical maximizers of egoistic utility, devoid of any capacity to reason in terms of human suffering. This is quite obviously not a description we wish to endorse. It has to be underscored that the reception of persons in need of protection encompasses important elements of altruism and compassion, which are irreducible to mere strategic thinking, ${ }^{262}$

Nonetheless, if we keep these risks and shortcomings in mind, the idea of cost management can still serve as a structuring device to explain why states do what they do in the area of extraterritorial protection. It helps in taking the perspective of an-admittedly fictive-rationally acting state. Now, from this perspective, what factors have a bearing on the costs of operating a protection system?

We suggest starting out with three general determinants:

1. the number of beneficiaries of extraterritorial protection present on the territory of the host state,

2. the level of individual rights accorded to these beneficiaries, and

3. the degree of burden sharing.

The relevance of these three determinants is rather self-evident: many beneficiaries, a high level of rights accorded to them, and no help from other states will yield high costs. A limited number of beneficiaries enjoying a low level of rights and forthcoming assistance from other states will yield low costs. Also, given that protection resources are assumed to

262 Some contributors to the burden-sharing debate have attempted to make systematic use of these elements to improve the efficiency of burden-sharing schemes. Drawing on a communitarian paradigm, Hathaway and Neve have proposed a temporary protection scheme that attempts to pool protection seekers and host countries sharing 'functional' and 'cultural' commonalities. The underlying assumption for both criteria is that such systematic pooling will improve host states' willingness to receive protection seekers. See J. Hathaway and M. A. Castillo, 'Temporary Protection', in J. Hathaway (ed.), Reconceiving International Refugee Law (1997, Martinus Nijhoff Publishers, The Hague), p. 16. 
be finite, each determinant affects the two remaining determinants. Low numbers may entail fiscal and political margins to accord a higher level of rights, and vice versa. Or, the availability of burden sharing may exonerate the purse of a state that would otherwise have slashed rights or restricted access to its territory. Beyond these simple dynamics, any combination of the three determinants can be imagined. Simplifying, one may claim that the total reception costs of a state are a function of all three determinants. We have attempted to visualize the interdependence of these three determinants in Figure 2.

This interdependence may take on many forms. A state receiving many protection claims due to its geographical situation may resort to a very restrictive practice of recognising beneficiaries in order to keep costs at bay. ${ }^{263}$ Or a state unable or unwilling to alter the level of individual rights may attempt to restrict access to its territory. This is an expression of the tension between immigration and integration..$^{264}$ Finally, states unable to manage inflows and to alter the level of individual rights may choose the strategy of burden sharing to limit costs.

${ }^{263}$ This relationship between access and legal interpretation has been acknowledged by the German Federal Minister of the Interior Otto Schily in an interview: 'Und seien wir doch einmal ehrlich: Die alte Fassung des Grundrechts auf Asyl hat den Menschen zwar das liberalste Zugangsrecht nach Deutschland verschafft, hatte aber zugleich die illiberalste Anerkennungspraxis in Europa zur Folge.' ['And let us be honest: the old version of the constitutional right to asylum resulted in the most liberal right to access to Germany, but entailed simultaneously the most illiberal recognition practice in Europe.' Translation by this author]. Das Asylrecht lässt sich nicht balten, Die Zeit, No. 44, 28 October 1999, p. 3. Indeed, the German restriction of the right to asylum entailed elevated recognition rates (In 1992, the Convention status recognition rate was 4.2 percent, while the corresponding number in 1994 was 7.5 percent. Source: UNHCR, Refugees and Others of Concern to UNHCR, 1998 Statistical Overview, (1999, Geneva), p. 72).

${ }^{264}$ For an excellent account of this tension, see J. Öberg, Gränslös rättvisa eller rättvisa inom gränser? Om moraliska dilemman i välfärdsstatens invandrings- och invandrarpolitik (1994, Almqvist \& Wiksell International, Uppsala), pp. 123-30. Öberg uses a matrix assembling four factors for structuring policy solutions: immigration policy can either be liberal or controlled, and integration policy can either be discriminating or equality-minded. To describe the unstable relationship between immigration and integration, Öberg suggests the metaphor of a seesaw. 


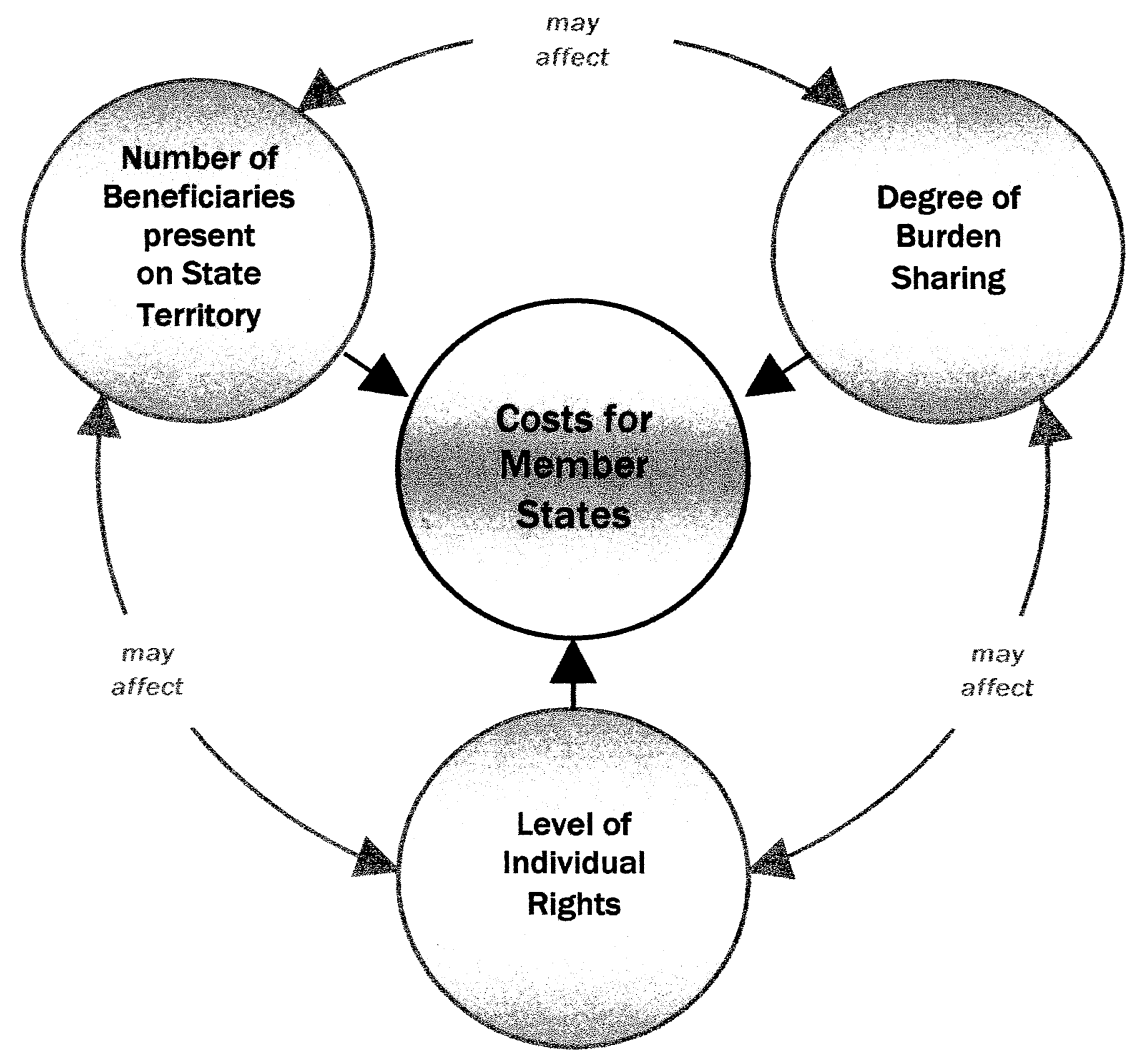

Figure 2: Three determinants affecting the costs of protection regimes 
We may now take another step and refine this crude model. The first two determinants-the number of beneficiaries and the rights accorded to them-can each be split up further. Looking at the number of beneficiaries, we may ask two questions: how many beneficiaries reach the territory of host states, and how long do they stay? Expressed simply, the regulation of entry and exit determines costs subsumed under the first determinant. It covers, first, the regulation of access to the territory of a host state and, second, the regulation of departure from that territory. Both areas of regulation will determine the number of beneficiaries present on the territory at a given point of time and the length of their stay. Entry regulation stretches over various forms of border controls as well as the enforcement of visa requirements. But we may also factor in safe third country arrangements, by which protection seekers may be removed immediately upon arrival in a formerly transited country. Ultimately, it is a matter of taste whether such arrangements are considered measures inhibiting entry or as speeding up exit. The decisive issue is that they impact the actual number of beneficiaries present in the host country. Finally, regulations on the termination of beneficiary status or measures on the physical enforcement of removal may be counted under the exit heading. Thus, the discussion on temporary protection is largely on the numerical limitation of beneficiaries, because one of its main issues is the replacement of permanent residence permits for certain beneficiaries with temporary ones. Precisely like the three general determinants, the regulation of entry and the regulation of exit are also interdependent. Confronted with a new inflow, a state may wish to promote the earlier return of beneficiaries who are already present. Conversely, where return is difficult due to the situation in the country of origin, a state may opt for blocking possible new inflows.

Moving on to the level of individual rights, we may split this determinant into procedure and substance. First, it is clear that procedures determining the status of protection seekers trigger costs. A simple group determination is cheaper than individual determination, and a differentiated system of multiple court appeals is more costly than an administrative decision-making process involving two tiers. ${ }^{265}$ The point in such procedures is to distinguish persons in need of protection from persons wishing to enter for other reasons-thus, to single out

265 This presupposes that the compared procedures converge at a minimum level of procedural standards. 


\section{CHAPTER 3}

beneficiaries. Second, equally obvious, the level of material rights accorded to beneficiaries is decisive for the costs of protection. Does protection merely imply that the presence of a beneficiary is tolerated? Or is the beneficiary entitled to housing, education and social assistance? Often, host countries operate with protection categories, splitting beneficiaries into distinct groups. Each category is linked to a certain level of rights. To name but one example, a refugee in the sense of the 1951 Refugee Convention usually enjoys a higher level of rights than a person protected under a Temporary Protection scheme. Just as was the case with entry and exit, the regulation of procedure and substance are principally interdependent as well.

The individual rights accorded to beneficiaries may include family reunion. This right is a special case. First and foremost, it relates to the second determinant, comprising the level of rights accorded. But as it also brings additional persons into the country, it possesses concurrently linkages to the first determinant, relating to the numbers of beneficiaries. Once more, it is a matter of choice whether to classify family members as beneficiaries of protection, or whether they should be counted under a separate heading. The issue of family reunion should serve as a caveat that the three determinants are not mutually exclusive in a strict sense.

We recall that the legal devices used to regulate the number of beneficiaries and the level of rights enjoyed by them work as a system of filters. Generally speaking, this system will allocate protection to the deserving cases, and reject those not in need of it. Whether it actually fulfils this task is quite another matter, and shall be scrutinized in later chapters. ${ }^{266}$

This leaves us with the third determinant-burden sharing-which cannot be described as a filter. What is the place of burden sharing in protection systems? Roughly, the management of costs entailed by such systems may be depicted as a zero-sum game. For a moment, let us imagine a situation in which protection needs are constant. A state restricting access to protection will cut its own costs, but increase the costs borne by the protection seeker, by another host state, or by both. Just like measures targeting the single protection seeker, burden sharing is a way of externalising costs. The difference lies in who shall bear the externalized costs. In the case of burden sharing, costs are not shifted to

\footnotetext{
${ }^{266}$ See chapters 5 to 7 below.
} 
the protection seeker, but to another, co-operating state. So burden sharing is about the consensual relationship between host states, rather than the non-consensual relationship between a host state and the individual protection seeker.

Due to its special characteristics, a separate chapter shall be dedicated to the issue of burden sharing. ${ }^{267}$ Suffice it here to note that the degree of burden sharing affects the shaping of a single state's protection system. This dynamic works both ways. Consensus among states on a burden sharing arrangement can improve the openness of protection afforded by their domestic protection systems. On the other hand, the absence of burden sharing may set off a spiral of restriction in domestic protection systems. Where one Member State introduces restrictive legislation, other Member States risk experiencing a consequential rise in the number of protection claims. Therefore, as in a game of domino, all other Member States will introduce restrictive laws as well.

\subsection{The Perspective of the Protection Seeker}

Let us reconsider the steering devices used by states from the perspective of the protection seeker, who attempts to enter the protection system set up by a potential host state. This gives us an opportunity to explain the most pertinent filter devices in some detail, and to reflect upon the counter-strategies used by the protection seeker. After all, her prime interest is to evade a threatening violation of human rights at home. ${ }^{268}$ As a corollary, she wants to maintain maximum control over the process of

\footnotetext{
${ }^{267}$ See chapter 8 below.

${ }^{268}$ The literature on the motivational factors determining flight decisions is comprehensive. Among the classics, we find Kunz and Richmond. E. F. Kunz, 'The Refugee in Flight: Kinetic Models and Forms of Displacement', 7 International Migration Review 125 (1973); E. F. Kunz, 'Exile and Resettlement: Refugee Theory', 15 International Migration Review 42 (1980); A. H. Richmond, 'Sociological theories of international migration: The case of refugees', in B. E. Harrell-Bond and L. Monahan (eds), The sociology of involuntary migration (1988, SAGE Publications, London) (a revised version of this paper was published in: Journal of Refugee Studies, vol. 6(1), 1993). For a good overview of scholarly writings and empirical research on the causes of refugee migration, see S. Schmeidl, 'Causes of Forced Exodus: Five Principal Explanations in the Scholarly Literature and Six Findings from Empirical Research', in A. P. Schmidt (ed.), Wither Refugee? The Refugee Crisis: Problems and Solutions (1996, PIOOM, Leiden).
} 


\section{CHAPTER 3}

flight, first and foremost to avert forcible return to the very threat she is fleeing, but also to secure a stable existence in the country of refuge. ${ }^{269}$

To the protection seeker, the legal devices used by states to regulate protection systems appear as hurdles on the road to safety. Let us reconstruct the order in which a would-be protection seeker is confronted with these devices before, during and after flight. Following her itinerary, we can separate them into three categories:

1. access to territory,

2. access to full-fledged procedures, and

3. access to protection.

We shall now take a thorough look at each of these categories.

\subsubsection{Access to Territory}

The first difficulty the protection seeker meets is gaining access to the territory of a potential host state. Two groups of norms impact access to territory. The first group comprises pre-entry measures. Their function is to steer the access of aliens-including protection seekers-to state territory by extraterritorial means of control. The second group comprises post-entry measures, which allow for the immediate allocation of a protection seeker to another state, cutting her territorial contact to an insignificant minimum.

The entry regulations set up by a potential host state represent the core of pre-entry measures. ${ }^{270}$ Generally, these comprise the demand for a valid passport and an entry visa. An entry visa is permission by the destination state to enter its territory. Such a visa must be sought before entering that state. Normally, one applies for a visa at a diplomatic representation of the destination country.

How are visa requirements enforced? Of course, states wish to deflect those not meeting its entry requirements as early as possible, so as to

${ }^{269}$ Crisp has pointed out that 'even those asylum seekers who merit refugee status have clear preferences in relation to their ultimate destination', deploring that the polarized debate on asylum in Western Europe does not accomodate such insights. Crisp, 1999, p. 5.

270 There are a number of factual impediments as lack of travel resources (money, infrastructure) or large geographical distances which are not of interest here. 
avoid any territorial contact. In this context, so-called carrier sanctions constitute an important complement to visa requirements. Such sanctions are imposed by destination states on airlines, ship-owners and other carriers who bring persons without the necessary documentationpassport and visa-into their territory. To evade these sanctions, carriers will check that passengers are in possession of such documentation before allowing them to embark. In fact, parts of the state border control have been moved over to the check-in counters at foreign airports-and into private hands. ${ }^{271}$ In addition, some states place immigration officers at points of embarkation abroad to train and assist local authorities as well as carriers in checking the completeness and authenticity of travel documents. ${ }^{272} \mathrm{~A}$ further step is to entice the authorities of third countries to exercise exit control. Thus, beyond the state border and the airline check-in counter, a third front is established where the border police of third countries inhibit the migration attempts of persons without the necessary documentation. ${ }^{273}$

Taken together, these measures aim at blocking the entry of undocumented migrants, among whom we find persons in need of protection; such measures have therefore been described under the heading of non-arrival ${ }^{274}$ or non-entrée ${ }^{275}$ policies. They constitute the first filter a would-be protection seeker meets. Where a visa requirement exists, and a visa is denied in accordance with the pertinent rules, a person in need of protection will not even be able to leave her country of origin. The only remaining option in such cases is to use informal channels: bribing an embassy officia! who issues visas, acquiring a falsified visa of

271 This diminishes the leeway for protection considerations. Already in 1989, Feller stated succintly that '[a] transportation company which is trying efficiently and profitably to move large numbers of passengers shares neither the motives, nor the expertise and training of State immigration authorities'. E. Feller, 'Carrier Sanctions and International Law', 1 IJRL 48 (1989), p. 57. See also la Cour Bødtcher A and J. Hughes, 'The effects of legislation imposing fines on airlines for transporting undocumented passengers', in M. Kjærum (ed.), The Effects of Carrier Sanctions on the Asylum System (1991, Danish Refugee Council, Copenhagen).

$272 \mathrm{~J}$. Vedsted-Hansen, Responding to the arrival of asylum seekers. Control vs. protection in asylum procedures, Paper prepared for the Technical Symposium on International Migration and Development, The Hague, Netherlands, 29 June-3 July 1998, Paper No. IX/2 (1998, Geneva), p. 15.

${ }^{273}$ Vedsted-Hansen, 1998, p. 16.

${ }^{274}$ Vedsted-Hansen, 1998, p. 14.

${ }^{275}$ J. Hathaway, 'The emerging politics of non-entrée', Refugees (1992), pp. 40-1. 


\section{CHAPTER 3}

sufficient quality, or evading border controls at large. There is a black market offering such services, and accepting them implies taking a risk. Clients of human smugglers ${ }^{276}$ are often subject to various forms of exploitation. ${ }^{277}$ In a separate chapter, we will look into how Member States use visa requirements as a regulatory device. ${ }^{278}$

While pre-entry measures are preventive, post-entry measures are reparative. Their aim is to cut short the presence of the protection seeker on state territory by allocating her to another country. To effectuate such an allocation without violating international refugee law and human rights law, states have devised the concept of safe third countries.

What is the thinking behind that concept? On the way to a destination state within the EU, a large number of protection seekers travel through other countries. Provided they deem one of the transit countries as safe, Member States do not consider a protection claim on its merits, if the claimant could have sought protection there. Instead, the protection seeker will be sent back to that transit country. Such deflective mechanisms are also described with the concept of protection elsewhere. ${ }^{279}$

A precondition to this form of deflection is the safety of the third country-meaning that a protection seeker is safe from refoulement to the country of origin. Thus, safe third country-arrangements acknowledge the possibility of a protection need. However, this need should be assessed and catered for in another country-the safe third country. Obviously, this reasoning denies the protection seeker the option to choose a country of protection. Nonetheless, this option is very valuable for the protection seeker, for at least two reasons. First, protection systems differ from

${ }^{276}$ Although the terms 'traffickers' and 'smugglers' are often used interchangeably in migration discourse, we shall follow the set-up of definitions elaborated by the United Nations Office for Drug Control and Crime Prevention. 'The smuggling of migrants can be defined as the procurement of illegal entry of a person into a State of which the latter person is not a national in order to obtain a profit. Trafficking can be defined as the recruitment, transportation or receipt of persons through deception or coercion for the purpose of prostitution, other sexual exploitation or forced labour.' United Nations Office for Drug Control and Crime Prevention, Global Programme against Trafficking in Human Beings. An outline for action, Vienna, February 1999, p. 5.

277 Such exploitation may take the form of ordinary fraud, i.e. charging for a service which is not rendered. Protection seekers have also been enticed to pay for being smuggled by trafficking drugs to their destination countries.

278 See chapter 5.1 .1 below.

279 UNHCR, Re-Admission Agreements, 'Protection Elsewhere' and Asylum Policy (August 1994, Geneva), Section 5. 
country to country, making it reasonable to choose a country where there are realistic prospects of protection. ${ }^{280} \mathrm{Or}$, in a worst case scenario, the safe third country may simply turn out not to be safe in practice, and a protection seeker returned there would soon find herself removed back to her country of origin. ${ }^{281}$ Second, non-legal factors, such as family ties, the existence of diasporas, or a common language may play an important role for the successful establishment of a new life in exile. ${ }^{282}$

To work properly, safe third country-arrangements presuppose the consent of the safe third country to take back protection seekers who have passed through its territory. This consent is often assured formally through the conclusion of a readmission agreement between destination states and transit states. ${ }^{283}$ At a later stage, we will look into the effects of a multilateral safe third country arrangement among Member States, based on the Dublin Convention. ${ }^{284}$

Following the itinerary of a typical protection seeker, we find that safe third country arrangements are the second hurdle on the way to the destination country. For the protection seeker, it is possible to circumvent

280 "For example, some countries will return an asylum-seeker to a "first country of asylum" if they are satisfied that he or she will have access there to fair procedures for the determination of refugee status under the 1951 Convention. No inquiry is made whether a refugee from armed conflict, who does not also fear persecution, would be granted protection in that country.' [Emphasis in the original]. UNHCR, Note on International Protection (submitted by the High Commissioner), 7 September 1994, UN Doc. No.A/AC.96/830, para. 43.

281 'UNHCR is aware of a number of instances where asylum-seekers have been refused admission and returned to a country through which they had passed, only to be summarily sent onwards from there, without an examination of their claim, either to their country of origin or to another, clearly unsafe country. Where asylum-seekers are returned to third countries, this needs to be implemented with due regard to the principle of non-refoulement. Without the prior consent and the co-operation of the country to which an asylum-seeker is returned, there is a grave risk that an asylumseeker's claim may not receive a fair hearing there and that a refugee may be sent on, directly or indirectly, to persecution, in violation of the principle of non-refoulement and of Article 33 of the 1951 Convention.' UNHCR, Note on the Principle of Nonrefoulement-EU Seminar on the Implementation of the 1995 EU Resolution on Minimum Guarantees for Asylum Procedures, November 1997, para. G.

${ }^{282}$ In recent years, the role of transnational social networks in the process of forced migration has received increased attention by researchers. For a brief overview of the significance of such networks and the research issues arising, see Crisp, 1999.

${ }^{283}$ For a typology of readmission agreements, see G. Noll, 'The Non-admission and Return of Protection Seekers in Germany', 9 IJRL 415 (1997a), pp. 416-24

${ }^{284}$ See chapter 5.2.1.1 below. 


\section{CHAPTER 3}

this hurdle by obfuscating her travel itinerary, destroying travel documents bearing traces of transit, and pretending that she has arrived directly from her country of origin. We shall see, however, that states seek to retaliate against such tactics. ${ }^{285}$

\subsubsection{Access to Full-fledged Procedures}

Let us now assume that the protection seeker has managed to reach the territory of a given destination country and has indeed filed a protection claim. Before this claim is fully examined on its merits, it has to pass another filter-whose implementation Member States secure through a variety of terminology and practical arrangements-all however with a common core: the denial of access to full-fledged determination procedures. Thus, certain cases are screened out on predominantly formal grounds.

This can be described as a two-tier process. First, a claim is screened regarding its admissibility. If, and only if, it passes the admissibility stage will it receive a full-fledged examination on its merits. In some Member States such formal screening is done in the framework of ordinary asylum procedures, while others deal with it in specific admissibility procedures. The rationale of admissibility procedures is to filter out cases that can be dealt with in a more expeditious manner, usually involving restricted legal safeguards and fewer appeal options. Such claims are often termed to be manifestly unfounded cases. ${ }^{286}$

Which cases are rejected at the admissibility stage? The range of such grounds is comprehensive and may vary among Member States. Common to all Member States is, however, the formal rejection of cases where the claimant could have sought protection in a safe third country.

As we have seen, safe third country-arrangements amount to a farreaching denial of an examination on the merits in the country of destination. ${ }^{287}$ This is, however, not the only category of cases where Member States cut down the profundity of examination. While we cannot

\footnotetext{
${ }^{285}$ On the procedural sanctions in the EU acquis, see chapter 6.1 below.

286 To speak of pending cases as 'manifestly unfounded' is a contradiction in terms, as the European Commission has observed. See text accompanying note 700 below.

${ }^{287}$ The denial is not total, however, as the protection seeker may challenge the presumption of safety, which leads to reasoning on the substance. See chapter 12.2 below.
} 
name all national practices in this overview ${ }^{288}$, the concept of safe countries of origin merits mentioning here. Under this concept, a full examination on the merits of each individual case is cut short through a formal presumption that the country of origin is safe. A protection seeker originating from a country of origin presumed to be safe will not receive a full-fledged examination of her claim unless she is able to rebut this presumption of safety. This concept has not been implemented by all Member States, but there are instruments of Union law alluding to it. Therefore, we shall revert to it in our later analysis. ${ }^{289}$

For protection seekers, procedural filters of admissibility represent a considerable challenge. Rebutting presumptions of safety can be a demanding task. In the single case, it may appear easier to circumvent the admissibility screening by misrepresenting the travel route or the country of origin. However, where detected, such misrepresentations strike against the overall credibility of the claimant, putting the success of the claim at risk.

\subsubsection{Access to Protection}

In the last set-up of filters, it is determined how much protection is meted out to a claimant who has passed the previous filters. Actually, these filters can be best described as a range of definitions. Most famous is probably the definition of the term 'refugee', to be found in the 1951 Refugee Convention and mirrored in the domestic legislation of Member States. Those who satisfy the criteria of this definition-as interpreted by the domestic decision-makers-are accorded a predefined package of rights. Usually, this package is the most beneficial one that protection systems have on offer. Nonetheless, protection options are not exhausted with Convention status. As we shall see, safety from return is also available under a number of international treaties for the protection of the individual, the content of which is sometimes mirrored in domestic legislation. Beyond that, domestic protection categories offer various alternatives, dubbed B-status, humanitarian status, war refugee status, temporary protection or otherwise. The delimitation of beneficiary

\footnotetext{
${ }^{288}$ For a more detailed comparison of state practice in Europe, North America and Australia, see IGCARMP, 1997, pp. 24-5.

${ }^{289}$ See chapters 6.1 and 6.2 below.
} 


\section{CHAPTER 3}

groups under these categories, as well as the rights enjoyed by them, vary from Member State to Member State. However, there are certain tendencies towards harmonisation, which we will track later on. ${ }^{290}$

In this context, we should recall that not all protection seekers whose claim is rejected in a final decision are removed from the territory of the state where protection was sought. For legal or factual reasons, deportation may be stayed temporarily. Legally, a person may not satisfy the exigencies of the refugee definition. Nonetheless, she may fall under the less demanding requirements of a mere prohibition of removal in domestic aliens' legislation. Factually, a rejected person may be unable to return, as there are no travel connections to her country of origin. Although stay of deportation places a person in a very volatile and precarious position, it represents a rudimentary form of protection and must therefore be counted under the present heading. Thus, it is insufficient to look exclusively at the filter consisting of status recognition. Our scrutiny must also extend to another filter-the law and practice of return.

To be classified in a favourable protection category, there are few other strategies than good legal representation and, where necessary, the full use of appeal options. Strategies such as claiming false nationalities or making up alternative accounts of persecution may appear promising to avert rejection in determination procedures, but in reality they weaken the credibility of those parts of the claim that correspond to the truth. Confronted with rejection in the last instance, an unknown number of protection seekers choose to avoid removal by going underground.

\subsection{Two Loops}

In the discussion above, taking the state perspective helped us to understand the rationale of control as well as the interdependence of the general determinants decisive for the layout, capacity and practical operation of protection systems. Switching to the perspective of the protection seeker, the steering devices used by states presented themselves as a differentiated set-up of filters, through which any successful protection claim has to pass. These steering devices pertained to both the system of migration control and the system of extraterritorial protection.

${ }^{290}$ See text accompanying note 737 below. 
Faced with them, the protection seeker develops a variety of counterstrategies. In turn, potential host countries react by trying to fix what they perceive as loopholes. Thus, taking a bird's eye view, state strategies and protection seeker strategies evoke and affect each other, and their relationship is probably best described as a dialectical one. We are faced with a loop, where governmental efforts of control and the individual quest for extraterritorial protection feed back into each other.

Crisp has described these dynamics very aptly with regard to the role of diasporas as facilitators of flight:

The hypothesis [...] is that by establishing and activating transnational social networks (aided to a considerable extent by new transport and communications technologies) a considerable number of asylum seekers were able to negotiate their way through the many obstacles to entry erected by the states of Western Europe. And the success of migration strategies was such that governments introduced ever more draconian measures (some of them in contravention of states' international legal obligations) to deter or prevent further arrivals. ${ }^{291}$

Let us for now disregard his assessment of the legality of governmental counter-measures and focus on the dynamics he describes. While statesand the electoral constituencies behind them-remain the formal masters of legislative measures in the field of extraterritorial protection and migration control, protection seekers actually affect the content of such measures by their evasive and compensatory strategies. Thus, we may conclude that the conflict between universalist and particularist perspectives is not confined to the political constituencies crafting laws. It is equally present in the loop of implementation, circumvention and amendment following their original adoption. While the single protection seeker is excluded from law making, she may indirectly affect this loop by her strategies of circumvention. This loop juxtaposes the protection seeker, in the universalist position, and the potential host state, in the particularist position.

To this loop between protection seeker and potential host state, we have to add the effects evoked by the degree of burden sharing among potential host states. This brings in a second feedback loop, which was

${ }^{291}$ Crisp, 1999, p. 10. 
described above ${ }^{292}$, where non-co-operation among states yields a spiral of restriction and co-operation produces openness. Even this loop features an interplay of particularist and universalist positions. After all, heavily burdened host states seeking to arrange for burden sharing pursue both their own self-interest and the interest of the protection seeker.

Looking at extraterritorial protection as a product of both loops lets us comprehend how contradiction and conflict emerge within law itself. In the next part of this work, we shall proceed to the law of the European Union, and clear our minds as to how it has regulated access to territory, to full-fledged procedures, and to protection. To do so, we shall set out by first summarising the flight movements confronting Europe throughout the last decade, and then look into the gradual development of the institutional framework seized with European integration during the same period.

\footnotetext{
${ }^{292}$ See chapter 3.1 above.
} 